University of Nebraska - Lincoln

DigitalCommons@University of Nebraska - Lincoln

Matrix-Assisted Laser Desorption/Ionization Time-of-Flight Mass

Spectrometry Characterization of Primary Amine End-

Functionalized Polystyrene and Poly(methyl methacrylate)

Synthesized by Living Anionic Polymerization Techniques

Haining Ji

Georgios Sakellariou

Jimmy W. Mays

Follow this and additional works at: https://digitalcommons.unl.edu/usdoepub

Part of the Bioresource and Agricultural Engineering Commons

Ji, Haining; Sakellariou, Georgios; and Mays, Jimmy W., "Matrix-Assisted Laser Desorption/lonization

Time-of-Flight Mass Spectrometry Characterization of Primary Amine End-Functionalized Polystyrene and Poly (methyl methacrylate) Synthesized by Living Anionic Polymerization Techniques" (2007). US Department of Energy Publications. 78.

https://digitalcommons.unl.edu/usdoepub/78

This Article is brought to you for free and open access by the U.S. Department of Energy at DigitalCommons@University of Nebraska - Lincoln. It has been accepted for inclusion in US Department of Energy Publications by an authorized administrator of DigitalCommons@University of Nebraska - Lincoln. 


\title{
Matrix-Assisted Laser Desorption/Ionization Time-of-Flight Mass Spectrometry Characterization of Primary Amine End-Functionalized Polystyrene and Poly(methyl methacrylate) Synthesized by Living Anionic Polymerization Techniques
}

\author{
Haining Ji, ${ }^{\dagger}$ Georgios Sakellariou, ${ }^{\dagger}$ and Jimmy W. Mays $*,+, \hbar$ \\ Department of Chemistry, University of Tennessee, Knoxville, Tennessee 37996, and Chemical Sciences \\ Division and Center for Nanophase Materials Sciences, Oak Ridge National Laboratory, Oak Ridge, \\ Tennessee 37831
}

Received December 19, 2006; Revised Manuscript Received February 1, 2007

\begin{abstract}
The reaction of living anionic polymers with 2,2,5,5-tetramethyl-1-(3-bromopropyl)-1-aza-2,5disilacyclopentane (1) was investigated using coupled thin layer chromatography and matrix-assisted laser desorption/ionization time-of-flight mass spectrometry. Structures of byproducts as well as the major product were determined. The anionic initiator having a protected primary amine functional group, 2,2,5,5-tetramethyl1-(3-lithiopropyl)-1-aza-2,5-disilacyclopentane (2), was synthesized using all-glass high-vacuum techniques, which allows the long-term stability of this initiator to be maintained. The use of $\mathbf{2}$ in the preparation of well-defined aliphatic primary amine $\alpha$-end-functionalized polystyrene and poly(methyl methacrylate) was investigated. Primary amino $\alpha$-end-functionalized poly(methyl methacrylate) can be obtained near-quantitatively by reacting 2 with 1,1-diphenylethylene in tetrahydrofuran at room temperature prior to polymerizing methyl methacrylate at $-78{ }^{\circ} \mathrm{C}$. When 2 is used to initiate styrene at room temperature in benzene, an additive such as $N, N, N^{\prime}, N^{\prime}-$ tetramethylethylenediamine is necessary to activate the polymerization. However, although the resulting polymers have narrow molecular weight distributions and well-controlled molecular weights, our mass spectra data suggest that the yield of primary amine $\alpha$-end-functionalized polystyrene from these syntheses is very low. The majority of the products are methyl $\alpha$-end-functionalized polystyrene.
\end{abstract}

\section{Introduction}

Well-defined primary amino end-functionalized polymers are of great importance in a number of technical fields. These materials have been extensively used as linking agents in the preparation of many complex macromolecular architectures. ${ }^{1,2}$ These materials are also of interest because they can be used to prepare polymer-grafted functional surfaces. ${ }^{3,4}$ Such modified functional surfaces are useful in a wide range of applications such as nanofillers, bioimplants, etc. Recently, a number of research groups have demonstrated that amino end-functionalized polymers can be used as macroinitiators to synthesize polymer-polypeptide block copolymers ${ }^{5,6}$ with potential applications in fields of controlled-release drug delivery and biomimetic assemblies.

Living anionic polymerization is the most promising strategy for the synthesis of well-defined primary amino end-functionalized polymers because, in addition to its ability to provide polymer backbones of predictable molecular weights with very low molecular weight distributions, ${ }^{7,8}$ functional groups can be installed at the $\alpha-, \omega$-, or both chain ends quantitatively or nearquantitatively using the appropriate functional initiator and/or terminator. ${ }^{9,10}$ A saturated hydrocarbon linear chain with a halo group at one end and the desired functional group at the other $\left[\mathrm{X}-\left(\mathrm{CH}_{2}\right)_{n}-\mathrm{FG}\right]$ is a common terminator combination. Functional initiator can be synthesized by the reaction of these functional terminators with lithium metal $\left[\mathrm{X}-\left(\mathrm{CH}_{2}\right)_{n}-\mathrm{FG}+\right.$ $\mathrm{Li}^{0} \rightarrow \mathrm{Li}-\left(\mathrm{CH}_{2}\right)_{n}-\mathrm{FG}+\mathrm{X}^{-}$. If the living anionic polymer chain ends are reactive toward the functional groups, two

\footnotetext{
* Corresponding author.

†niversity of Tennessee.

$\doteqdot$ Oak Ridge National Laboratory.
}

strategies can be applied: (1) postpolymerization reactions to convert the chain ends into desired functional groups and (2) development of protective moieties that are stable toward the living anionic polymer chain ends and can be later converted into the desired functional groups.

Hoye and co-workers ${ }^{11}$ developed a method for synthesizing primary amine end-functionalized polymers by living anionic polymerization plus postpolymerization reactions. The polymer backbone was synthesized first using living anionic polymerization techniques and was then terminated with a halo group. In the postpolymerization reaction step, azidation and reduction reactions were used to convert the halo group into a primary amine group. Quirk and Cheng ${ }^{12}$ reported a one-pot synthesis of primary amine end-functionalized polystyrene (PS) by adding poly(styryl)lithium solution to a reagent generated from methoxyamine and methyllithium at $-78^{\circ} \mathrm{C}$. The amino end-capped PS was obtained in $92 \%$ yield. The very low reaction temperature of this method, however, limits its application. Recently, Quirk and co-workers ${ }^{13}$ reported a room temperature synthesis of primary amine end-functionalized PS. In this method, the living anionic polymers were first end-functionalized with hydrosilane groups $(-\mathrm{SiH})$ followed by addition of the primary amine groups through hydrosilylation reaction.

In attempts to develop a terminating reagent that could afford well-defined primary amine end-functionalized polymers without postpolymerization reactions at ambient temperature, Nakahama and co-workers ${ }^{15,16}$ reported that $N$-(benzylidene)trimethylsilylamine reacts efficiently with polystyryl- and polyisopropenyllithium and that the corresponding primary amine endfunctionalized polymers can be obtained in yields up to $90 \%$. However, Quirk and Summers ${ }^{17}$ later reexamined these reactions and reported that only $69 \%$ of the desired end-functional 
polymers were obtained due to side reactions. Schulz and Halasa ${ }^{14}$ demonstrated that the $-\mathrm{NSi}\left(\mathrm{CH}_{3}\right)_{3}$ moiety is stable toward the living anionic polymers and can be easily converted to primary amine group by exposing them to acidic protons. Ueda et al..$^{19}$ then developed 2,2,5,5-tetramethyl-1-(3-bromopropyl)-1-aza-2,5-disilacyclopentane (1) as a protected amineterminating reagent. These authors claimed that reactions of $\mathbf{1}$ and polystyryl- and polyisopropenyllithium produce aliphatic primary amine end-functionalized polymers with $95+\%$ degrees of amination. In addition, DeSimone and co-workers ${ }^{20}$ developed a chlorosilane derivative, [N,N-bis(trimethylsilyl)amino]butylchlorodimethylsilane, and Schlaad and co-workers ${ }^{21}$ developed a slightly different terminating reagent, 1-(chlorodimethyldilyl)3 -[N,N-bis(trimethylsilyl)amino]propane, for synthesis of primary amine functionalized polymers.

In order to synthesize primary amine $\alpha$-end-functionalized polymers, the development of protected amine initiators is necessary. Schulz and Halasa ${ }^{14}$ prepared amino end-functionalized poly(diene)s using $p$-lithio- $N, N$-bis(trimethylsilyl)aniline as initiator. This hydrocarbon-insoluble initiator produced polymers with rather broad molecular weight distributions. Jerome and co-workers ${ }^{22}$ recently described the synthesis of the protected amine anionic initiator, 2,2,5,5-tetramethyl-1-(3lithiopropyl)-1-aza-2,5-disilacyclopentane (2), by the reaction of 1 and lithium metal. They demonstrated the synthesis of primary amine $\alpha$-end-functionalized poly(methyl methacrylate) using the resulting initiator and also claimed that the initiator obtained from their synthesis is not stable for long-term storage, even at $-20^{\circ} \mathrm{C}$. It should also be noted that their evaluation of the efficiency of the initiator is based on whether well-defined polymers can be obtained or not. No end-group analysis was reported. Manners and co-workers ${ }^{23}$ have also investigated the synthesis of amino-protective anionic initiator by the reaction of compound $\mathbf{1}$ and lithium metal and claimed that the cyclic disilyl protecting group was not stable to organolithium reagents, in contrast to the report by Jerome and co-workers. ${ }^{22}$ They observed that the lithiation of compound $\mathbf{1}$ had led to a subsequent rearrangement and formed an eight-member ring structure. An X-ray diffraction image of the crystal of this rearranged initiator was provided.

Herein, we report the characterization of the primary amine end-functionalized polymers synthesized by functional terminator (1) and initiator (2) in detail using a combination of thin layer chromatography (TLC) and matrix-assisted laser desorption/ionization time-of-flight mass spectrometry (MALDI-TOF MS). This method is capable of providing information on endgroup structures of polymers with molecular weight lower than $1 \times 10^{4} \mathrm{~g} / \mathrm{mol}^{24-26}$ In this work, the synthesis of 2 using allglass high-vacuum techniques in order to improve the stability of the initiator is also explored.

\section{Experimental Section}

Materials. All chemicals used in this work were purchased from Aldrich Chemical. Monomers (styrene, methyl methacrylate), solvents (benzene, tetrahydrofuran (THF)), lithium chloride ( $\mathrm{LiCl})$, 1,1-diphenylethylene (DPE), $N, N, N^{\prime}, N^{\prime}$-tetramethylethylenediamine (TMEDA) and methanol were purified according to a standard procedure. $^{24,25}$ 2,2,5,5-Tetramethyl-1-(3-bromopropyl)-1-aza-2,5disilacyclopentane (1) was stirred over $\mathrm{CaH}_{2}$ for at least $24 \mathrm{~h}$ before being distilled into an all-glass ampule equipped with a break-seal. Lithium powder was used as received.

Synthesis of the Primary Amine Protective Initiator, 2,2,5,5Tetramethyl-1-(3-lithiopropyl)-1-aza-2,5-disilacyclopentane (2), Using the All-Glass High-Vacuum Technique. A drawing of the custom-made apparatus for the reaction of $\mathbf{1}$ and lithium metal is

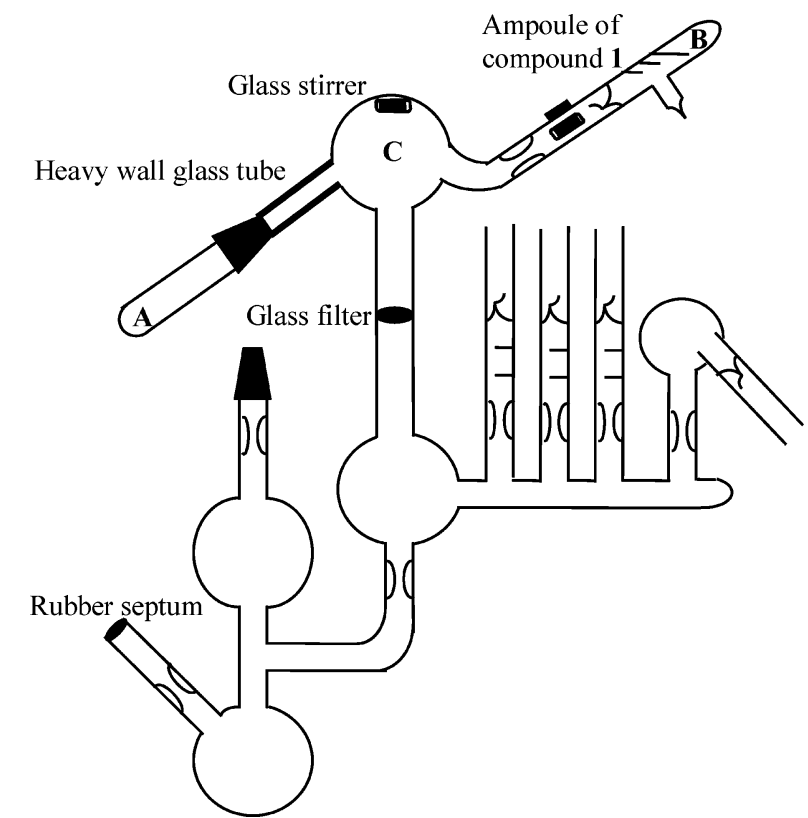

Figure 1. An all-glass apparatus for the synthesis of protected primary amine initiator 2,2,5,5-tetramethyl-1-(3-lithiopropyl)-1-aza-2,5-disilacyclopentane.

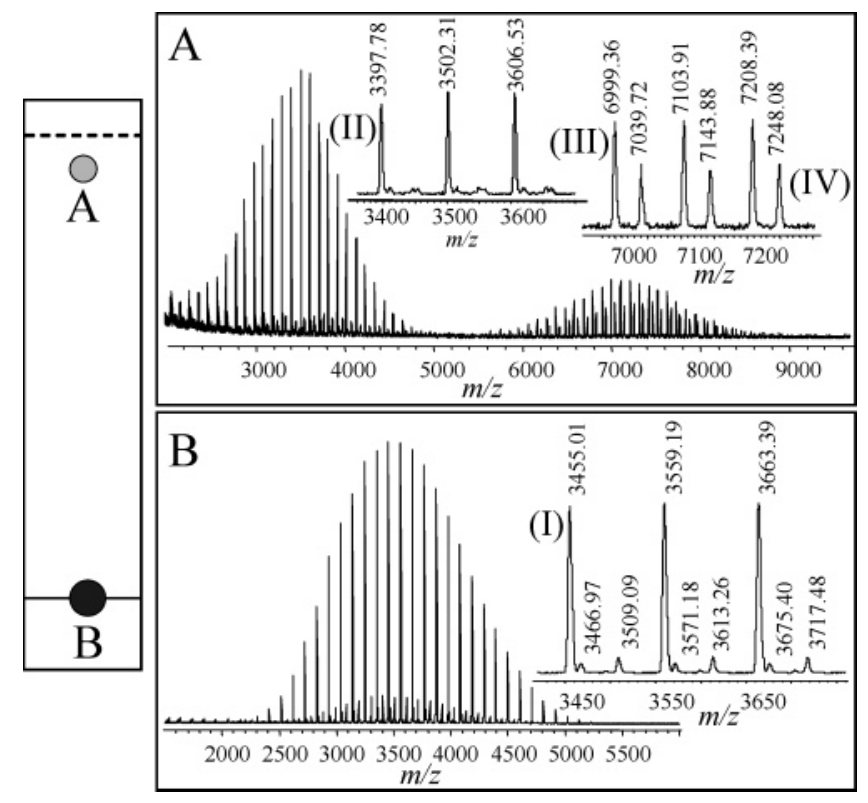

Figure 2. Thin layer chromatography/matrix-assisted laser desorption/ ionization time-of-flight mass spectrometry analysis of a polystyrene sample synthesized using the protected primary amine terminator.

displayed in Figure 1. The apparatus was docked to the high-vacuum line and then filled with inert gas. Approximately $10 \mathrm{~g}$ of lithium metal was added to ampule A through the ground-glass joint. The apparatus was left to degas until high vacuum was achieved. A hexane solution $(4 \mathrm{~mL})$ of $n$-BuLi $(1.6 \mathrm{M})$ was injected into the apparatus through the rubber septum on the side arm in the purge section. This side arm was sealed at the constriction. Purified benzene $(\sim 100 \mathrm{~mL})$ was in-distilled to the apparatus. The apparatus was again degassed and then detached from the vacuum line. The lithium powder was collected into the reactor $\mathrm{C}$, and the heavy wall glass path between the reactor and the ampule was sealed shut. The $n$-BuLi solution was used to rinse the inside wall of the apparatus and the surface of the lithium powder thoroughly. The excess $n$-BuLi and the impurities were chased to the purge section. Benzene was back-distilled into the reactor, and the purge section was detached from the reactor. The apparatus was set in a position so that the lithium powder and the benzene were gathered in reactor 


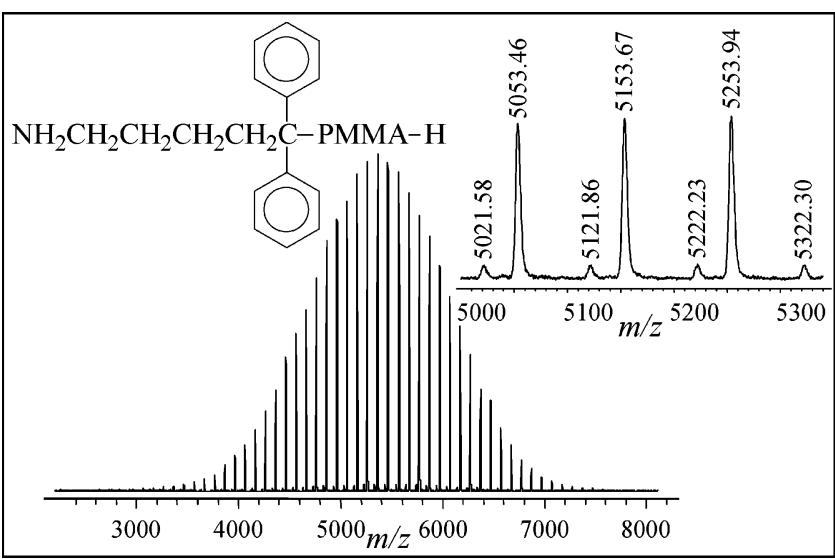

Figure 3. Matrix-assisted laser desorption/ionization time-of-flight mass spectrometry analysis of a poly(methyl methacrylate) sample synthesized using the protected primary amine initiator (raw product).

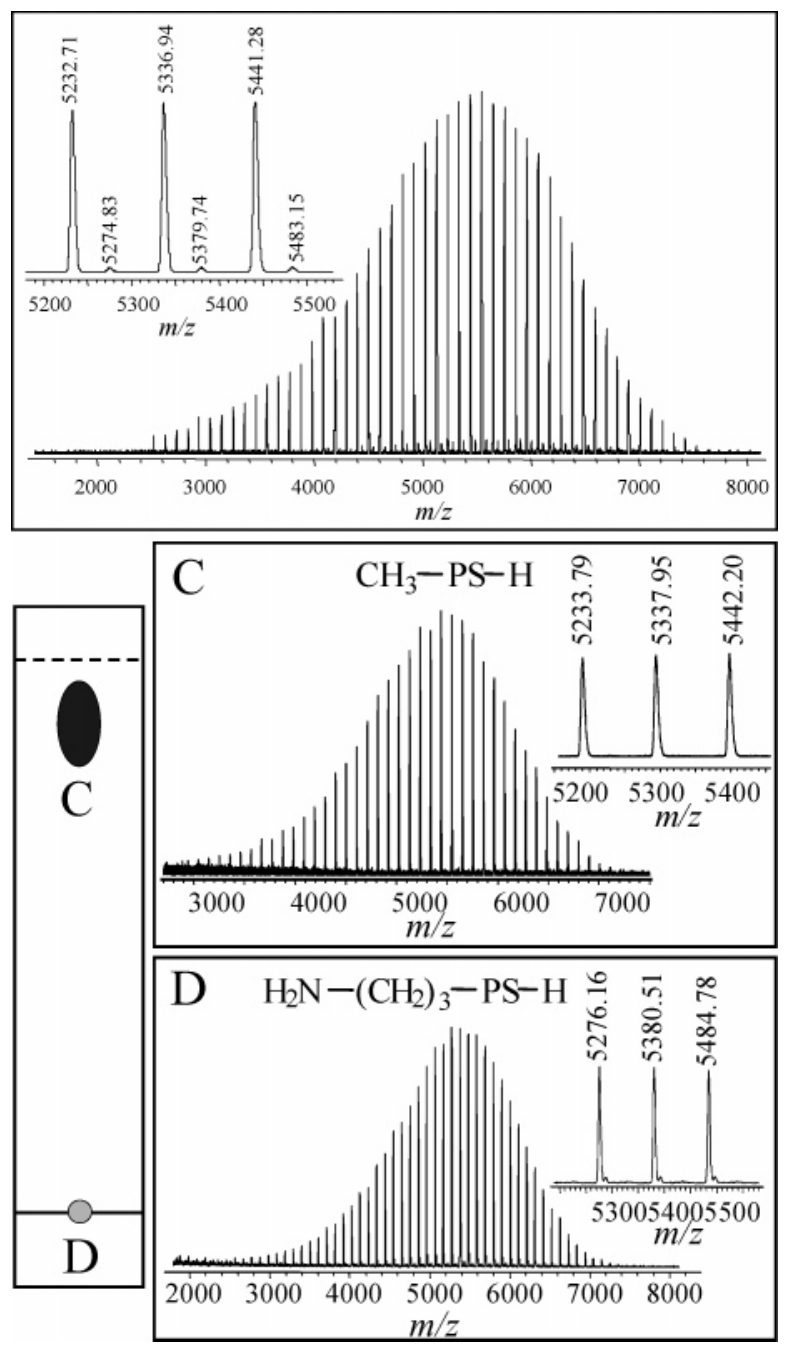

Figure 4. (top) Matrix-assisted laser desorption/ionization time-offlight mass spectrum of a polystyrene sample synthesized using the protected primary amine initiator (raw product). (bottom) The corresponding thin layer chromatography/matrix-assisted laser desorption/ ionization time-of-flight mass spectrometry analysis.

C. The reactor was immersed in an ice-water bath and kept at $0{ }^{\circ} \mathrm{C}$. Purified 1 (total $6 \mathrm{~mL}$ ) was added into the reactor $\mathrm{C}$ at the rate of $1 \mathrm{~mL} / \mathrm{h}$ while the lithium dispersion was stirred briskly. After the contents were added, the mixture was continued with briskly stirring at $0{ }^{\circ} \mathrm{C}$ for $4 \mathrm{~h}$, after which it was slowly warmed up to room temperature. The total reaction time was $18 \mathrm{~h}$ from the first addition of $\mathbf{1}$. The reaction mixture was then poured through

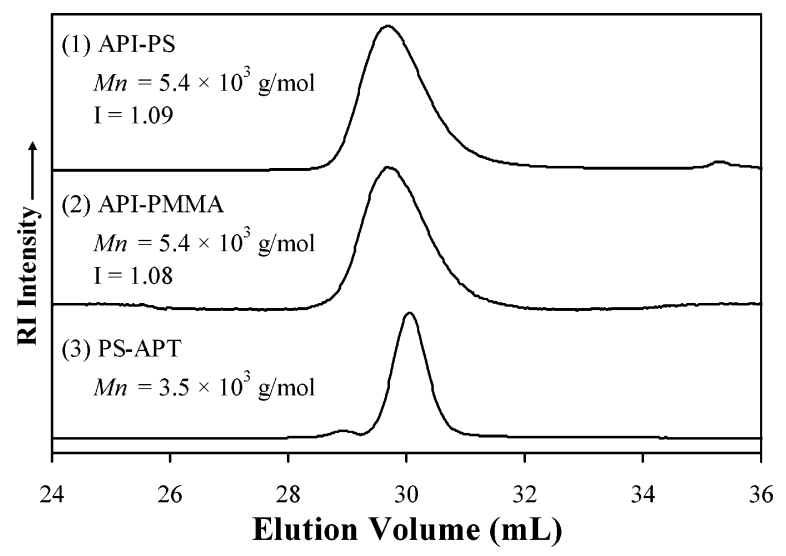

Figure 5. Size exclusion chromatography traces of (1) polystyrene synthesized using the protected primary amine initiator (API-PS), (2) poly(methyl methacrylate) synthesized using the protected primary amine initiator (API-PMMA), and (3) polystyrene synthesized using the protected primary amine terminator (PS-APT).

the glass filter. The clear colorless filtrate was sealed in the ampules and kept at $-20{ }^{\circ} \mathrm{C}$ until further use.

Synthesis of Primary Amine $\omega$-End-Functionalized PS. Primary amine $\omega$-end-functionalized PS was synthesized by the reaction of living poly(styryl)lithium anions and $\mathbf{1}$. Poly(styryl)lithium was synthesized in benzene according to a standard procedure $^{27,28}$ using sec-butyllithium as initiator. This initiator was synthesized in our laboratory by the reaction of sec-butyl chloride and lithium metal. ${ }^{27}$ Purified THF $(\sim 1 \mathrm{~mL})$ was added to the living poly(styryl)lithium/benzene solution and mixed thoroughly. Purified $1([1] / \mathrm{Li} \approx 1.1)$ was added. The characteristic orange-red color of the living poly(styryl)lithium anions disappeared immediately after mixing. The glass reactor was opened to the atmosphere, and the $\omega$-end-functionalized PS was obtained by precipitation into a 10 fold excess of methanol.

Polymerization of Styrene Using Protected Primary Amine Initiator (2). Purified styrene (4.0 g) and initiator $2\left(8.0 \times 10^{-4}\right.$ mol) were mixed with $50 \mathrm{~mL}$ of purified benzene at room temperature under high vacuum in an all-glass reactor whose interior had been cleaned thoroughly according to a standard procedure. ${ }^{27,28}$ The mixture remained clear and colorless, indicating that $\mathbf{2}$ does not initiate anionic polymerization of styrene under the above conditions. TMEDA $(\sim 1 \mathrm{~mL})$ was added to this mixture, and the color turned deep red immediately. This is means that with a small amount of TMEDA as additive the anionic polymerization of styrene in benzene takes place at room temperature. The polymerization was allowed to proceed for around $3 \mathrm{~h}$, and $\sim 1 \mathrm{~mL}$ of degassed methanol was then added to terminate the polymerization. The polymer was collected by precipitation into a 10 -fold excess of methanol.

Synthesis of Primary Amine $\alpha$-End-Functionalized PMMA. Purified DPE $\left(\sim 2.0 \times 10^{-3} \mathrm{~mol}\right)$ and the initiator $2\left(9.0 \times 10^{-4}\right.$ mol) were added to $100 \mathrm{~mL}$ of purified THF at $-78{ }^{\circ} \mathrm{C}$ in an allglass high-vacuum reactor whose interior had been cleaned thoroughly according to the standard procedure. ${ }^{27}$ The mixture solution remained colorless, indicating that $\mathbf{2}$ does not react with DPE at $-78{ }^{\circ} \mathrm{C}$ in THF. When the mixture solution was slowly raised to room temperature, a deep red color developed, indicating reaction between 2 and DPE. This living anion solution was allowed to stand at room temperature for $2 \mathrm{~h}$ to ensure complete reaction. An additive, lithium chloride ( $\mathrm{LiCl}, 0.5 \mathrm{M}$ solution in THF, $6 \mathrm{~mL}$, $3 \times 10^{-3} \mathrm{~mol}$ ), was added. The solution was then cooled to $-78^{\circ} \mathrm{C}$. Purified MMA (4.5 g) was slowly distilled into the initiator solution over a period of $1 \mathrm{~h}$. The reaction continued at $-78^{\circ} \mathrm{C}$ for another half an hour, and then $\sim 1 \mathrm{~mL}$ of degassed methanol was added. The reactor was opened to the atmosphere, and about $10 \mathrm{~mL}$ of methanol was added. The resulting solution was stirred at room temperature for $24 \mathrm{~h}$ to remove the protective moiety. The primary amine $\alpha$-end-functionalized PMMA was collected by 
Table 1. List of the Structures Determined from the Thin Layer Chromatography/Matrix-Assisted Laser Desorption/Ionization Time-of-Flight Mass Spectrometry Analysis of a Polystyrene Sample Synthesized Using the Protected Primary Amine Terminator

\begin{tabular}{|c|c|c|c|}
\hline Peaks & Structures & $\begin{array}{l}\text { Calculated } \\
\text { Mass (Da) }\end{array}$ & $\begin{array}{l}\text { Observed } \\
\text { Mass (Da) }\end{array}$ \\
\hline I & $\mathrm{CH}_{3} \mathrm{CH}_{2} \mathrm{CH}_{\mathrm{CH}}-\mathrm{CH}_{2}-\mathrm{CH}-\mathrm{CH}_{2} \mathrm{CH}_{2} \mathrm{CH}_{2} \mathrm{NH}_{2}$ & $\begin{array}{l}3454.88 \\
3559.13 \\
3663.38\end{array}$ & $\begin{array}{l}3455.01 \\
3559.19 \\
3663.39\end{array}$ \\
\hline II & $\mathrm{CH}_{3} \mathrm{CH}_{2}{ }_{\mathrm{CH}} \mathrm{H}-\mathrm{CH}_{2}-\mathrm{CH}_{\mathrm{n}}^{-}$ & $\begin{array}{l}3397.76 \\
3502.01 \\
3606.26\end{array}$ & $\begin{array}{l}3397.78 \\
3502.31 \\
3606.53\end{array}$ \\
\hline III & $\mathrm{CH}_{3} \mathrm{CH}_{2} \mathrm{CH}_{\mathrm{CH}}\left[\mathrm{CH}_{2}-\mathrm{CH}\right]_{\mathrm{N}}\left[\mathrm{CH}-\mathrm{CH}_{2}-{ }_{\mathrm{CH}_{3}} \mathrm{CHCH}_{2} \mathrm{CH}_{3}\right.$ & $\begin{array}{l}6999.01 \\
7103.27 \\
7207.53\end{array}$ & $\begin{array}{l}6999.36 \\
7103.91 \\
7208.39\end{array}$ \\
\hline IV & 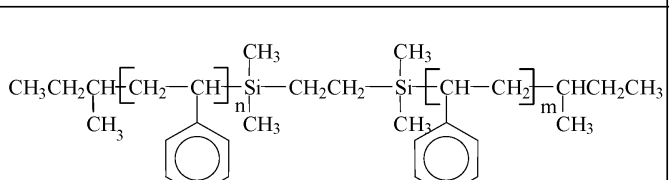 & $\begin{array}{l}7039.15 \\
7143.41 \\
7247.67\end{array}$ & $\begin{array}{l}7039.72 \\
7143.88 \\
7248.08\end{array}$ \\
\hline
\end{tabular}

repeated precipitation from THF solution into 10-fold excess of $n$-hexanes followed by drying in a vacuum oven.

TLC/MALDI-TOF MS Analysis. TLC was used to separate polymers according to their end groups, but not their molecular weights. Silica gel $\left(\mathrm{SiO}_{2}\right)$-based TLC plates (Scientific Absorbent Inc., Atlanta, GA) were used. The developing solvent was toluene (HPLC grade, Aldrich) and was used as received. Starting solutions were made at $50 \mathrm{mg} / \mathrm{mL}$. A short-wave UV lamp $(\lambda=254 \mathrm{~nm})$ was used to detect the polymer spots.

A Bruker Daltonics Autoflex II MALDI-TOF MS unit was employed to obtain mass spectra. Data processing was carried out with the FlexAnalysis program. trans,trans-1,4-Diphenyl-1,3-butadiene (DPB) was used as the matrix, and silver trifluoroacetate (AgTFA) was used as the ionization reagent for the analysis of PS samples. In the case of PMMA, 2,5-dihydroxybenzoic acid (DHB) was used as matrix, and no ionization reagent was added. Solutions of matrix $(20 \mathrm{mg} / \mathrm{mL})$, polymer $(5 \mathrm{mg} / \mathrm{mL})$, and cationic reagent $(5 \mathrm{mg} / \mathrm{mL})$ were prepared in THF. In the case of the TLC/MALDITOF MS coupling method, polymer solutions were prepared by adding $50 \mu \mathrm{L}$ of THF to the corresponding TLC spots to extract the polymers. Subsequently, $20 \mu \mathrm{L}$ of matrix solution was mixed with $1 \mu \mathrm{L}$ of ionization reagent solution and $1-10 \mu \mathrm{L}$ of the polymer solution. A volume of $1 \mu \mathrm{L}$ of the mixture solution was applied to the sample target, and the solvent was evaporated in air (the dried droplet method ${ }^{29}$ ). All measurements were carried out in positive ion and linear mode. The mass scale was calibrated externally using standard peptides.

${ }^{1}$ H NMR Measurements. A Bruker AMX400 spectrometer (Bruker Instruments, Karlsruhe, Germany) was used to collect the NMR spectra reported. A wide bore Oxford/Spectrospin magnet of $9.4 \mathrm{~T}(400.13 \mathrm{MHz})$ field strength was used. Typical ${ }^{1} \mathrm{H}$ parameter settings include temperature $=305 \mathrm{~K}$, relaxation delay $=30 \mathrm{~s}$, and solvent $=$ deuterated choloroform $\left(\mathrm{CDCl}_{3}\right)$. The sample concentration was $20 \mathrm{mg} / \mathrm{mL}$, and the internal standard was the residual proton chloroform signal of deuterated chloroform (7.24 ppm downfield from tetramethylsilane).

Size Exclusion Chromatography (SEC) Measurements. SEC was used to determine the average molecular weights and polydispersity indices, $M_{\mathrm{w}} / M_{\mathrm{n}}$, of the polymer samples with respect to polystyrene standards (Polymer Standards Service, Germany). The instrument was equipped with an isocratic pump (Knauer K-501), a RI detector (Knauer RI-K2301), and two linear PSS SDV gel columns: one LinearS and one $100 \AA$ (both $8 \times 600 \mathrm{~mm}$ ). Polymer Standards Service WinGPC software was used to acquire and analyze the chromatograms. A 5\% (v/v) triethylamine in THF solution was used as the mobile phase, and the flow rate was set at $1 \mathrm{~mL} / \mathrm{min}$. The use of triethylamine here is to prevent the interaction between the primary amine end groups and the stationary phase. All measurements were conducted at $30{ }^{\circ} \mathrm{C}$.

\section{Results and Discussion}

One of the known side reactions accompanying the reaction of living anionic polymers with halo compounds is "halo-lithium exchange". The addition of a small amount Lewis base, such as THF, can break down the chain end aggregation and increase the reactivity of the living anionic polymers, thereby increasing the reaction rate of the living anionic polymer toward the halo compound and reducing the extent of "halo-lithium exchange" side reaction. ${ }^{10}$ The TLC image of a primary amine $\omega$-endfunctionalized polystyrene sample obtained from the reaction of poly(styryl)lithium and $\mathbf{1}$ in benzene solution at room temperature with THF as additive is displayed in Figure 2. The MALDI-TOF mass spectra of the polymer fractions after TLC separation are also shown in this figure. A small portion of the raw product gathered at spot $\mathrm{A}$, and the majority of the product remained at the origin (spot $\mathrm{B}$ ) after the chromatographic separation. The MALDI-TOF mass spectrum of spot A contains three main distributions of peaks: one centered at the targeted molecular weight and the other two centered at twice this value. The MALDI-TOF mass spectrum of spot B is also shown in the figure. All peaks in mass spectra A and B are ionized by the silver cation. Mass spectrum B does not contain any dimeric species. The major distribution of peaks in this mass spectrum can be assigned as the targeted product (structure I). In mass spectrum A, all three distributions of peaks match the structures II, III, and IV proposed in the reaction scheme shown beneath the mass spectra. Structure II might result from impurities that 

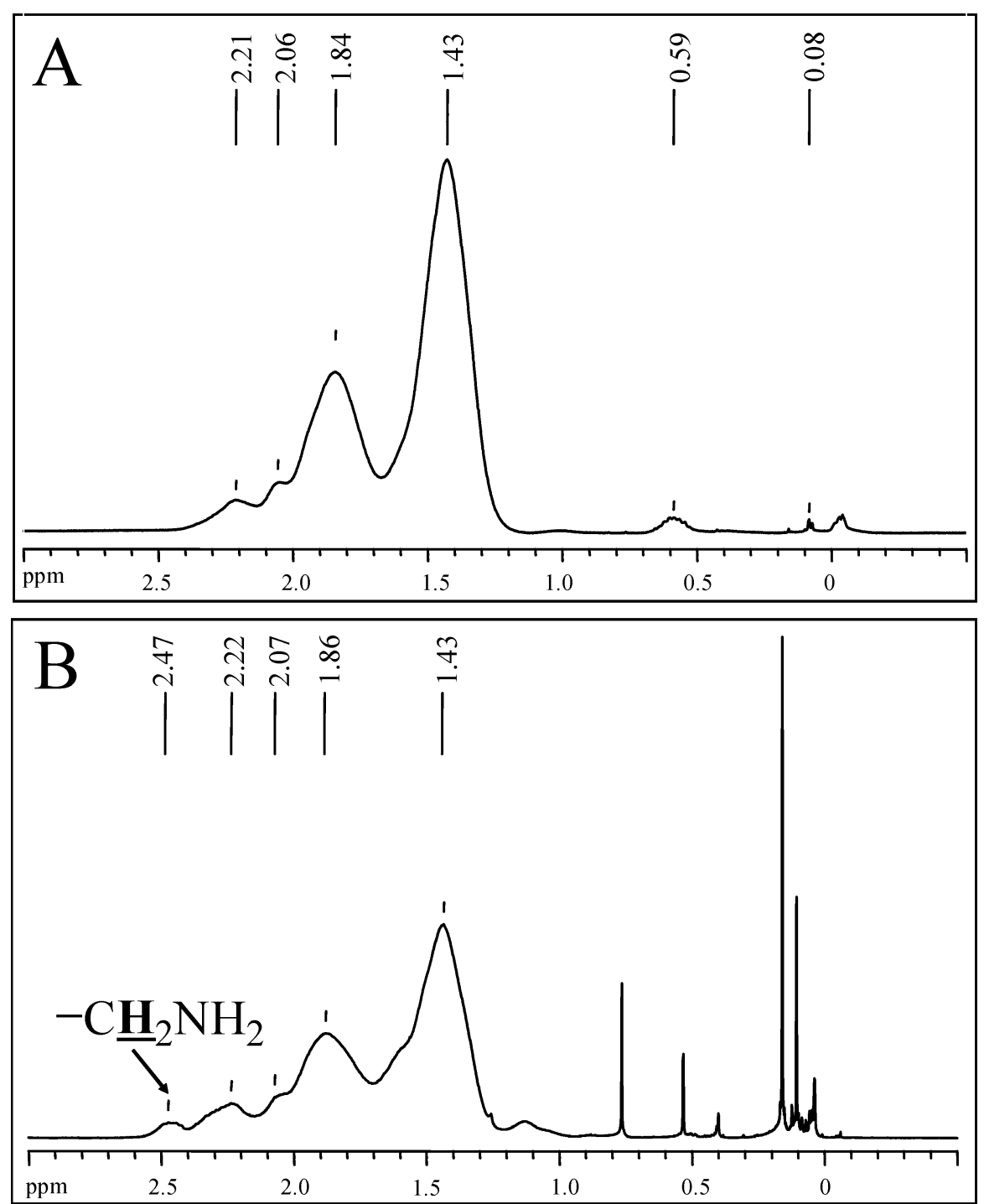

Figure 6. ${ }^{1} \mathrm{H}$ NMR spectra of (A) a polystyrene sample synthesized in benzene at room temperature using 2,2,5,5-tetramethyl-1-(3-lithiopropyl)1-aza-2,5-disilacyclopentane as initiator and TMDEA as additive and (B) a polystyrene sample obtained from the reaction of poly(styryl)lithium and 2,2,5,5-tetramethyl-1-(3-bromopropyl)-1-aza-2,5-disilacyclopentane.

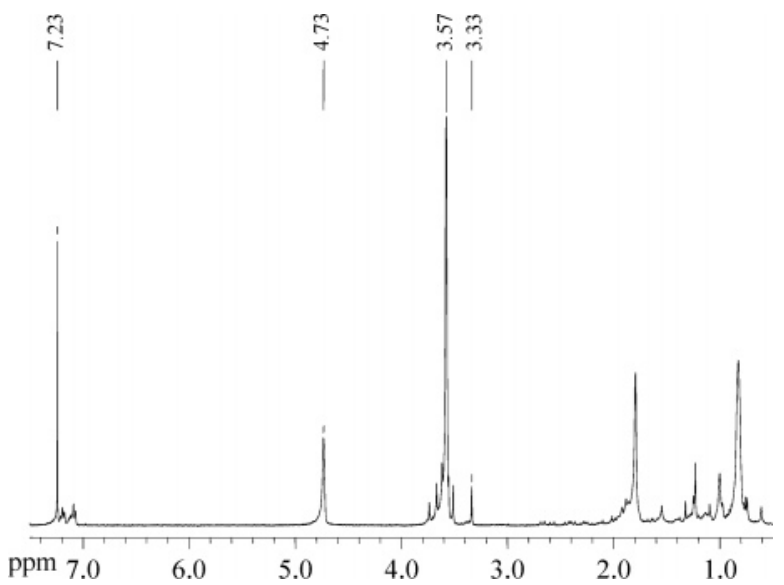

Figure 7. ${ }^{1} \mathrm{H}$ NMR spectrum of a poly(methyl methacrylate) sample synthesized using the protected primary amine initiator.

cannot be removed by our purification procedure. Structure III is the product from the Wurtz coupling reaction, where poly(styryl)lithium reacts with poly(styryl)bromine due to the "bromo-lithium exchange" side reaction. Structure IV is the product of two poly(styryl)lithium chains attacking the $\mathrm{Si}-\mathrm{N}$ bonds in the same molecule and is present in trace amounts.
The presence of this byproduct indicates that the $\mathrm{Si}-\mathrm{N}$ bonds are not completely stable toward the living anionic polymers at room temperature. The structures determined from these mass spectra along with their calculated and observed masses are listed in Table 1 . The structures of the peaks with lower intensity than those on the list could not be determined.

Jerome and co-workers ${ }^{23}$ recently published a procedure for the synthesis of the amino-protective functional initiator by the reaction of 1 with lithium dispersion in cyclohexane (at 30$40{ }^{\circ} \mathrm{C}$ ) or a mixture of cyclohexane and diethyl ether (at -20 ${ }^{\circ} \mathrm{C}$ ). This group reported that the initiator thus prepared could not be stored at $-20{ }^{\circ} \mathrm{C}$ for more than 2 days without losing its activity. Converting this initiator into a more stable form by adding 1 mol equiv of DPE increased its storage time to several days. We repeated this reaction using an all-glass high-vacuum technique ${ }^{24}$ designed to eliminate all possible impurities during the synthesis and to maintain the resulting initiator in an absolutely clean environment upon storing. This initiator, when made using our synthetic procedure, can be stored in the allglass apparatus at $-20^{\circ} \mathrm{C}$ for more than 6 months without losing activity. Freshly made initiator and initiator aged for 6 months gave identical polymers in terms of controllable molecular weights and narrow polydispersities. 
We first tested the initiator from our synthetic method by using it to synthesize primary amine $\alpha$-end-functionalized poly(methyl methacrylate). When this initiator, 2,2,5,5-tetramethyl1-(3-lithiopropyl)-1-aza-2,5-disilacyclopentane (2), was mixed with about $1.2 \mathrm{~mol}$ equiv of DPE in THF solution at $-78^{\circ} \mathrm{C}$, the characteristic deep red color of the diphenyl carbanion in THF was not observed, indicating that no reaction occurred. The $\mathrm{N} \rightarrow \mathrm{Li}$ aggregation should account for the low reactivity of 2 toward DPE at $-78{ }^{\circ} \mathrm{C}$. We let the temperature of this solution slowly increase to room temperature. A deep red color appeared, indicating the aggregation disassociated and $\mathbf{2}$ has been converted into 2,2,5,5-tetramethyl-1-(5,5,5-diphenyllithiopentanyl)-1-aza-2,5-disilacyclopentane. This DPE-capped functional initiator was used to initiate anionic polymerization of methyl methacrylate in THF at $-78^{\circ} \mathrm{C}$. Well-defined polymer in terms of both narrow molecular weight distribution and controllable molecular weights was obtained.

The MALDI-TOF mass spectrum of a PMMA sample made from this protected primary amine initiator $\mathbf{2}$ is displayed in Figure 3. The structure shown in the figure is assigned to the major distribution of peaks. Each of these peaks is ionized by a lithium cation. For example, the peak corresponding to a mass of 5153.67 Da consists of 49 monomer units $\left(M_{0}=100.15 \mathrm{Da}\right)$ and the end groups $\left(\mathrm{C}_{17} \mathrm{H}_{21} \mathrm{~N}, M=239.28 \mathrm{Da}\right)$ plus the lithium adduct $(M=7.0 \mathrm{Da})$. The calculated mass of $5153.63 \mathrm{Da}$ is in near-perfect agreement with the measured mass. The lithium ion is the dominant adduct here because lithium chloride was used as additive during the polymerization of methyl methacrylate. Complete removal of this adduct is extremely difficult. In fact, MALDI-TOF MS measurements of this sample were also conducted using sodium trifluoroacetace (NaTFA) and potassium trifluoroacetate (KTFA) as ionization reagents, and the resulting spectra were identical with the one we obtained without any addition ions. Using another matrix material, trans-3indoleacrylic acid (IAA), also resulted in a spectrum with the same peaks. The minor peaks in this spectrum were probably caused by the backbiting side reaction, which is the major side reaction occurring in the polymerization of methyl methacrylate.

Because of the $\mathrm{N} \rightarrow \mathrm{Li}$ aggregation, initiator $\mathbf{2}$ does not initiate the anionic polymerization of styrene in benzene at room temperature. Adding a drop of TMEDA can break down the aggregation and activate the polymerization. When THF was used instead of TMEDA, polymerization still did not occur. The TLC/MALDI-TOF analysis of a PS sample thus synthesized is illustrated in Figure 4. A MALDI-TOF mass spectrum of the raw product is shown in this figure, and two distributions of peaks can be observed. Peaks in the distribution of lower abundance match the mass of the targeted amino $\alpha$-endfunctionalized PS. The majority of the product appears to have a methyl head group. A TLC process can separate these two distributions of peaks and the image along with the MALDITOF mass spectra of the resulting spots are also displayed in Figure 4. A large portion of the product showed high mobility, indicating the absence of the primary amine functional groups. The MALDI-TOF mass spectrum of this spot confirms that this fraction is the major component in the raw product. A small portion of the product stays at origin and its MALDI-TOF mass spectrum contains only one distribution of peaks, whose masses match the structures of the targeted product: primary amine $\alpha$-end-functionalized polystyrene. Based on the above evidence, methyllithium was produced when initiator $\mathbf{2}$ was in contact with TMEDA and became the initiator for the majority of the product. The mechanism of this rearrangement is, however, not clear to us at this point.
These three polymers were also characterized using SEC, and the chromatograms are shown in Figure 5. Traces 1 and 2 were obtained for a PS sample made from primary amine protective initiator (API-PS) and a PMMA sample made from primary amine protective initiator (API-PMMA), respectively. In both cases, the observed number-average molecular weight, $M_{\mathrm{n}}(5.4$ $\times 10^{3} \mathrm{Da}$ from both SEC and MALDI-TOF MS), is in close agreement with the target $M_{\mathrm{n}}\left(5.0 \times 10^{3} \mathrm{Da}\right)$. The $M_{\mathrm{w}} / M_{\mathrm{n}}$ values of these two samples are low (1.09 for API-PS and 1.08 for API-PMMA), indicating high reactivity of the initiator when used in benzene with TMEDA as additive or in cold THF. Trace 3 was obtained for a polystyrene sample synthesized using the protected primary amine terminator (PS-APT). A small high mass peak caused by the presence of dimeric materials can be clearly observed. These dimeric species are also observed in the MALDI-TOF mass spectrum of this sample (Figure 2A).

Proton NMR was also used to characterize these three samples. Figure 6 depicts (A) the API-PS sample synthesized in benzene at room temperature using $\mathbf{2}$ as initiator and TMDEA as additive and (B) the PS-APT sample obtained from the reaction of poly(styryl)lithium and $\mathbf{1}$. The signal centered at a chemical shift of $2.47 \mathrm{ppm}$ accounts for the methylene protons adjacent to the primary amine group. It is clear that sample B contains primary amine group while sample A does not. Figure 7 shows a ${ }^{1} \mathrm{H}$ NMR spectrum of the API-PMMA. Signals of chemical shift at $2.4 \sim 2.5$ ppm can be observed, but these signals are difficult to distinguish from the background noise and thus cannot be quantified reliably. End-group analysis of polymers has long been a challenge for NMR and other conventional analytical techniques because the signals from the end groups are often very weak as compared to those from the polymer backbones.

\section{Conclusions}

We have demonstrated herein the use of coupled thin layer chromatography and matrix-assisted laser desorption/ionization time-of-flight mass spectrometry to investigate the reaction of living poly(styryl)lithium macroanions with 2,2,5,5-tetramethyl1-(3-bromopropyl)-1-aza-2,5-disilacyclopentane (1). When the reaction was carried out in benzene at room temperature with a small amount of tetrahydrofuran as additive, the targeted primary amine $\omega$-end-functionalized PS can be obtained. Three byproducts were detected, including the proton-terminated PS, the dimeric product from the "halo-lithium exchange" side reaction, and the dimeric product form two living polymer chains attacking the $\mathrm{N}-\mathrm{Si}$ bonds in the same terminating reagent. The synthesis of the amino-protective anionic initiator, 2,2,5,5tetramethyl-1-(3-lithiopropyl)-1-aza-2,5-disilacyclopentane (2), by means of an all-glass high-vacuum technique was reported in detail. Primary amine $\alpha$-end-functionalized poly(methyl methacrylate) can be synthesized in high yield by reaction of this initiator with 1,1-diphenylethylene in THF at room temperature followed by polymerization of methyl methacrylate at $-78^{\circ} \mathrm{C}$. When this initiator was used at room temperature, an additive such as TMEDA was necessary to activate the anionic polymerization. However, our mass spectra data suggest that the yield of primary amine $\alpha$-end-functionalized polystyrene from these syntheses was very low. The major product was methyl $\alpha$-end-functionalized polystyrene.

Acknowledgment. The authors thank Dr. Jamie Messman from the Chemical Science Division of Oak Ridge National Laboratory for performing some of the MALDI-TOF mass spectrometry measurements. We also thank Dr. Durairaj Baska- 
ran from Polymer Science and Engineering Division of National Chemical Laboratory in Pune, India, for his helpful advices. This work was supported by the National Science Foundation through their Collaborative Research in Chemistry Program (CRC-CHEM 0304807).

\section{References and Notes}

(1) Harth, E.; Bosman, A.; Benoit, D.; Helms, B.; Frechet, J. M.; Hawker, C. J. Macromol. Symp. 2001, 174, 85-92.

(2) Kubo, M.; Takeuchi, H.; Ohara, T.; Itoh, T.; Nagahata, R. J. Polym. Sci., Polym. Chem. 1999, 37, 2027-2033.

(3) O'Brien, C. P.; Rice, J. K.; Dadmun, M. D. Eur. Polym. J. 2004, 40, $1515-1523$.

(4) Orr, C. A.; Cernohous, J. J.; Guegan, P.; Hirao, A.; Jeon, H. K.; Macosko, C. W. Polymer 2001, 42, 8171-8178.

(5) Aliferis, T.; Iatrou, H.; Hadjichristidis, N. Biomacromolecules 2004, $5,1653-1656$

(6) Schlaad, H.; Antonietti, M. Eur. Phys. J. E 2003, 10, 17-23.

(7) Hong, K.; Uhrig, D. W.; Mays, J. W. Curr. Opin. Solid State Mater. Sci. 1999, 4, 531-538.

(8) Hadjichristidis, N.; Pitsikalis, M.; Pispas, S.; Iatrou, H. Chem. Rev. 2001, 101, 3747-3792.

(9) Hirao, A.; Hayashi, M. Acta Polym. 1999, 50, 219-231.

(10) Hsieh, H. L.; Quirk, R. P. Anionic Polymerization Principles and Practical Application; Marcel Dekker: New York, 1996.

(11) Cernohous, J. J.; Macosko, C. W.; Hoye, T. R. Macromolecules 1998, $31,3759-3763$.

(12) Quirk, R. P.; Cheng, P. L. Macromolecules, 1986, 19, 1291-1294.

(13) Quirk, R. P.; Kim, H.; Polce, M. J.; Wesdemiotis, C. Macromolecules 2005, 38, 7895-7906.
(14) Schulz, D. N.; Halasa, A. F. J. Polym. Sci., Polym. Chem. Ed. 1977, $15,2401-2410$

(15) Hattori, I.; Hirao, A.; Yamaguchi, K.; Nakahama, S.; Yamazaki, N. Makromol. Chem. 1983, 184, 1355-1362.

(16) Hirao, A.; Hattori, I.; Sasagawa, T.; Yamaguchi, K.; Nakahama, S. Makromol. Chem., Rapid Commun. 1982, 3, 59-63.

(17) Quirk, R. P.; Summers, G. J. Br. Polym. J. 1990, 22, 249-254.

(18) Quirk, R. P.; Lynch, T. Macromolecules 1993, 26, 1206-1212.

(19) Ueda, K.; Hirao, A.; Nakahama, S. Macromolecules 1990, 23, 939945.

(20) Peters, M. A.; Belu, A. M.; Linton, R. W.; Dupray, L.; Meyer, T. J.; DeSimone, J. M. J. Am. Chem. Soc. 1995, 117, 3380-3388.

(21) Kildegard, K.; Schlaad, H.; Falkenhagen, J.; Kruger, R. Macromolecules 2002, 35, 7157-7160.

(22) Varshney, S.; Song, Z.; Zhang, J.; Jerome, R. J. Polym. Sci., Polym. Chem. 2006, 44, 3400-3405.

(23) Wang, Z.; Lough, A.; Manners, I. Macromolecules 2002, 35, 76697677.

(24) Ji, H.; Nonidez, W. K.; Mays, J. W. Int. J. Polym. Anal. Charact. 2002, 7, 181-194.

(25) Ji, H.; Sato, N.; Nonidez, W. K.; Mays, J. W. Polymer 2002, 43, 71197123 .

(26) Ji, H.; Nonidez, W. K.; Advincula, R. C.; Smith, G. D.; Kilbey II, S. M. D.; Dadmun, M. D.; Mays, J. W. Macromolecules 2005, 38, 99509956.

(27) Uhrig, D.; Mays, J. W. J. Polym. Sci., Polym. Chem. 2005, 43, 61976222.

(28) Hadjichristidis, N.; Iatrou, H.; Pispas, S.; Pitsikalis, M. J. Polym. Sci., Part A: Polym. Chem. 2000, 38, 3211-3234.

(29) Karas, M.; Hillenkamp, F. Anal. Chem. 1988, 60, 2299-2301. MA062909T 